\title{
Lipoprotein(a): An update on its role in human health and disease
}

\section{Amalia-Despoina Koutsogianni' ${ }^{1}$, Evangelos Liberopoulos², Alexandros D. Tselepis ${ }^{3}$}

\author{
'Department of Internal Medicine, Faculty of Medicine, University of loannina, loannina, Greece \\ ${ }_{2}^{2} 7^{\text {st }}$ Propaideutic Department of Medicine, School of Medicine, National and Kapodistrian University \\ of Athens, Laiko General Hospital, Athens, Greece \\ ${ }^{3}$ Atherothrombosis Research Centre / Laboratory of Biochemistry, Department of Chemistry, University \\ of loannina, loannina, Greece
}

\begin{abstract}
Over the past few years, there has been an undiminished interest on lipoprotein(a) [Lp(a)]. High Lp(a) levels have been proposed as an independent causal risk factor for atherosclerotic cardiovascular disease (CVD). The main question that remains to be answered, however, is the potential clinical benefit of $L p(a)$ reduction. This will contribute to the enrichment of our knowledge on the exact pathophysiological role of this lipoprotein. This narrative review aims to summarize currently available data on the structure, metabolism, and pathogenicity of $L p(a)$.
\end{abstract}

KEY WORDS: Lipoprotein(a), Apolipoprotein(a), Oxidized Phospholipids, Lipoprotein-associated phospholipase A2, Autotaxin, Monocyte chemoattractant protein-1, Atherogenesis, Calcific aortic valve stenosis, Thrombosis

\section{INTRODUCTION}

Lipoprotein(a) [Lp(a)] was first discovered by the Norwegian physician Kare Berg almost 6 decades ago. It is a lipoprotein particle found in plasma consisting of a lowdensity lipoprotein (LDL) particle with an apolipoprotein(a) [apo(a)] moiety covalently bound to its apolipoprotein B-100 (apoB-100) component ${ }^{1-3}$. High Lp(a) levels are inherited in $90 \%$ of cases ${ }^{4}$. Lp(a) exerts inflammatory, thrombotic and atherogenic properties and seems to represent an independent cardiovascular risk factor ${ }^{1-4} . \mathrm{Lp}(\mathrm{a})$ mediates

\section{Corresponding author:}

Alexandros D. Tselepis, MD, PhD

Professor of Biochemistry-Clinical Chemistry

Department of Chemistry, University of loannina

45110 loannina, Greece

Tel: +30 2651008365 , Fax: +30 2651008785 ,

E-mail: atselep@uoi.gr atherogenesis through mechanisms linked to its LDL and apo(a) components and associated oxidized phospholipids (OxPLs), of which $\operatorname{Lp}(a)$ is their major lipoprotein carrier ${ }^{5}$. Elevated Lp(a) plasma concentrations may predict the presence and progression of coronary heart disease (CHD), femoral and carotid artery disease ${ }^{6}$. Furthermore, $\mathrm{Lp}$ (a) levels seem to increase following acute coronary syndrome and percutaneous coronary intervention, due to its role as a positive acute-phase reactant. High Lp(a) levels, may predict death, myocardial infarction, stroke and need for revascularization in unselected populations, as well ${ }^{6}$. They also correlate with an amplified risk of aortic valve stenosis and peripheral artery disease ${ }^{6}$. Notably, there are currently no available treatments for potent reduction of high $\mathrm{Lp}$ (a) levels. In this narrative review, we present an update on the metabolism, physiology, and pathophysiology of $\operatorname{Lp}(\mathrm{a})$.

Submission: 09.09.2021, Acceptance: 16.11.2021 


\section{METHODS}

Relevant studies were identified by searching MEDLINE, EMBASE and CENTRAL databases up to 31 August 2021 using the following terms: lipoprotein(a), apolipoprotein(a), Lp-PLA2, oxidized phospholipids, cardiovascular risk, atherogenesis, calcific aortic valve stenosis, thrombosis. Reference lists from these articles were also scrutinized.

\section{Structure and metabolism of $\operatorname{Lp}(a)$}

Lp(a) consists of an LDL-like particle, in which the apoB100 is linked by a single disulphide bridge to a unique plasminogen-like glycoprotein, known as apolipoprotein(a). (Figure) Lp(a) exerts inflammatory, oxidative, thrombotic, atherogenic and antifibrinolytic properties ${ }^{1-3}$.

$\mathrm{Lp}$ (a) synthesis occurs exclusively in the liver. Approximately $90 \%$ of circulating $L p(a)$ levels are inherited and strongly determined by a single gene, the $L P A$ gene ${ }^{7}$. The $L P A$ gene is evolutionarily derived from and highly homologous to the plasminogen (PLG) gene $\mathrm{g}^{8,9}$. The PLG gene encodes 5 unique kringle domains and an active protease domain that is activated to plasmin by tPA (tissue-type plasminogen activators). The LPA gene, and therefore apo(a), does not contain kringles
I-III, but does contain kringle IV (KIV), KV and a protease domain. This protease domain is catalytically inactive and, thus, it cannot be converted to a plasmin-like molecule because of amino acid substitutions at the site of cleavage of plasminogen activators ${ }^{10}$. Furthermore, because of multiple duplication events during evolution, the LPA gene has accumulated 10 copies of KIV that are each unique in amino acid sequence except for KIV2. KIV contains 1 copy of KIV1 and KIV3-10, but variable copies of KIV2, ranging from 1 to $>40$ on each allele. KIV2 repeats may differ in nucleic acid sequence but are identical in amino acid sequence ${ }^{10}$. Consequently, the different repeats of KIV2 in apo(a) account for the various size polymorphisms of this apolipoprotein. Besides the apo(a) isoform size, however, other genetic variants have an impact on $\mathrm{Lp}(\mathrm{a})$ levels for a given isoform. Functional single nucleotide polymorphisms (SNPs) within the $L P A$ KIV2-encoding region $(+4733 \mathrm{G}>\mathrm{A},+4925 \mathrm{G}>\mathrm{A}$, $\mathrm{R} 21 \mathrm{X}$, rs41272114, rs3798220) cooperate in determining $\mathrm{Lp}(\mathrm{a})$ variance and induce low $\mathrm{Lp}(\mathrm{a})$ concentrations $\mathrm{s}^{11-15}$. This moderate but lifelong genetic $L p(a)$ reduction translates to noticeable CHD risk reduction, as well ${ }^{11,14,15}$. KIV9 contains an unpaired cysteine residue, which is attached by a disulfide bridge to a cysteine residue of

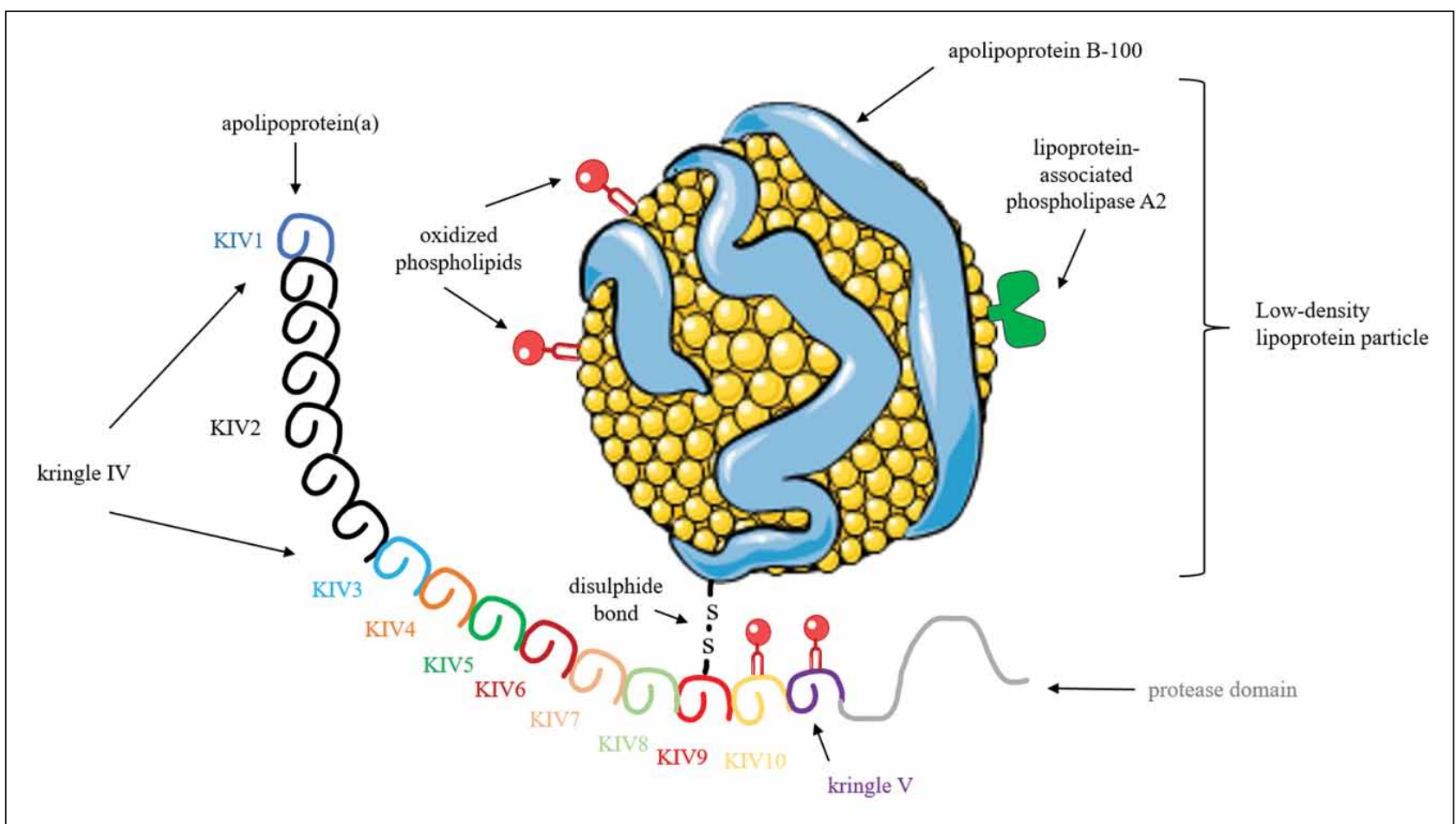

FIGURE. Structure of lipoprotein(a). Lipoprotein(a) [Lp(a)] consists of a low-density lipoprotein-like particle, in which the apolipoprotein B-100 is linked by a single disulphide bond to a glycoprotein, known as apolipoprotein(a). Apolipoprotein(a) contains 10 copies of kringle IV (KIV), KV and a catalytically inactive protease domain. KIV contains 1 copy of KIV1 and KIV3-10, but variable copies of KIV2, ranging from 1 to $>40$ on each allele. Up to $90 \%$ of all oxidized phospholipids found in human lipoproteins are carried on Lp(a) and subjected to degradation by lipoprotein-associated phospholipase A2. 
apoB-100, located near the binding site of LDL to its receptor ${ }^{16-18}$. Specific functionalities relevant to the assembly and molecular pathology of $\mathrm{Lp}(\mathrm{a})$ are attributable to lysine-binding sites (LBSs), which are present in some of the KIV domains of apo(a). The lysine-binding site in KIV10 is considered to be strong and those in KIV5KIV8 weak $^{19}$. The strong lysine-binding site in KIV10 is thought to mediate binding of apo(a)-Lp(a) to fibrin, cell surface receptors and extracellular matrix proteins ${ }^{18,20}$. On the other hand, those in KIV5-KIV8 participate in the non-covalent interactions with apoB100 that precede disulfide bond formation ${ }^{21,22}$. Importantly, KIV10 also contains the site to which a proinflammatory oxidized phospholipid (OxPL) is covalently attached ${ }^{23,24}$.

As mentioned above, plasma $\mathrm{Lp}(\mathrm{a})$ levels vary widely between individuals and are largely determined by their apo(a) size ${ }^{13}$. There is an inverse relationship between the number of KIV2 repeats of apo(a) and the level of Lp(a) in plasma ${ }^{25}$. Unlike other traditional lipoproteins, lifestyle changes have little impact on $\mathrm{Lp}(\mathrm{a})$ levels ${ }^{1,4}$. Furthermore, $L p(a)$ levels are stable over time. Thus, $L p(a)$ levels need only be measured once, unless a secondary cause is suspected or specific treatment is instituted ${ }^{1,4}$.

Unfortunately, little is known about the dominant sites and processes accountable for the removal of $L p(a)$ from circulation. Scientists debate between liver and kidneys as the dominant clearance site. Spleen and muscles may also play a modest role in the clearance process ${ }^{7}$. Multiple receptors for $L p(a)$ have been identified, with the best evidence available for the LDL receptor (LDLR) ${ }^{26-29}$, various plasminogen receptors ${ }^{29,30}$ and scavenger receptor class B member 1 (SRB1) ${ }^{31}$. Lp(a) concentrations may vary with ethnicity and gender ${ }^{4}$. Traditional thresholds for elevated Lp(a) concentrations are $>30 \mathrm{mg} / \mathrm{dL}$ (>75 nmol/L), with about $20 \%$ of the population having $L p(a)$ concentrations $>50 \mathrm{mg} / \mathrm{dL}(120 \mathrm{nmol} / \mathrm{L})^{1,32}$.

\section{Physiological functions of $\operatorname{Lp}(\mathrm{a})$}

The physiological role of $\mathrm{Lp}(\mathrm{a})$ in humans is still not fully elucidated. Individuals with extremely low levels of plasma $\mathrm{Lp}$ (a) present with no disease or deficiency syndromes ${ }^{33}$. In a large, contemporary, general population cohort low levels of $L p(a)$ and corresponding $L P A$ genotypes did not associate with any major disease groups, including cancer, cancer subtypes and infections. For cardiovascular disease (CVD) was even found that observationally and genetically low levels of $L p(a)$ are associated with decreased risk of myocardial infarction, aortic valve stenosis, and ischaemic stroke $^{34}$. Several studies have reported that $L p(a)$ plays a significant role in inhibiting angiogenesis and tumor growth $^{35-37}$. Lp(a) due to its homology with PLG may func- tion as an anti-neoplastic protein. It may decrease the activation of the proteases, which are mandatory for the activation of matrix metalloproteinases (MMPs) and the subsequent activation of angiogenesis ${ }^{33}$. Moreover, many investigators have reported the positive role of $L p(a)$ in wound healing and tissue repair, by limiting bleeding at sites of injury and delivering cholesterol for cell replenishment ${ }^{33,38,39}$. Indeed, $\mathrm{Lp}(\mathrm{a})$ accumulates in endothelial injuries, binds to several components of the vessel wall and sub-endothelial matrix, stimulates chemotactic activation of monocytes/macrophages and modulates angiogenesis. All these effects are mediated by apo(a) ${ }^{33}$.

As previously described, apo(a) isoforms share substantial structural and functional homology with PLG, the principal component of the fibrinolytic pathway, which is converted to plasmin for fibrinolysis ${ }^{35}$. This homology allows apo(a) to compete with PLG for fibrin affinity sites ${ }^{40}$. Additionally, Lp(a) attenuates PLG activation to plasmin by the tissue Plasminogen Activator (tPA) in the presence of fibrin ${ }^{41}$. Thus, $L p(a)$ seems to inhibit fibrinolysis. However, there is little evidence to support such a role in vivo. Many studies have reported that $L p(a)$ levels increase in patients with acute pathologies, such as myocardial infarction, inflammatory bowel disease, and gallbladder fistula ${ }^{33,42-44}$. It is hypothesized that under certain settings, after myocardial infarction for example, $\mathrm{Lp}(\mathrm{a})$ acts as a positive acute-phase reactant ${ }^{33,45}$. This is why inflammatory status should always be considered when interpreting plasma Lp(a) concentrations ${ }^{33,46,47}$. In contrast, Lp(a) may behave as a negative acute-phase reactant in cases of serious burns and severe infection, such as visceral leishmaniasis or sepsis ${ }^{48-50}$.

OxPLs play a fundamental role in the early stages of atherosclerosis ${ }^{5,51}$. It has been suggested that a normal physiologic role of $\mathrm{Lp}(\mathrm{a})$ may be to bind and transport such proinflammatory OxPLs. Because of its high content with lipoprotein-associated phospholipase A2 (Lp-PLA2), which hydrolyzes OxPLs, Lp(a) may also mediate their clearance. This occurs through the formation of a covalent bond between the KIV10 and KV of the apo(a) fragment of $L p(a)$ and OxPLs $s^{5,51}$.

\section{The pathogenicity of lipoprotein(a)}

Convincing evidence has emerged from pathophysiological, epidemiological, and genetic studies on the causality of high serum $\mathrm{Lp}(\mathrm{a})$ levels as a potent risk factor for CHD, transient ischaemic attack, ischaemic stroke or recurrent stroke in patients younger than 60 years, peripheral artery disease, chronic kidney disease, heart failure, venous thromboembolism, calcific aortic valve stenosis,

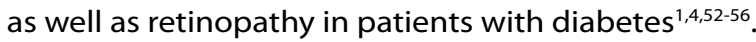


Moreover, Mendelian randomization and genome wide association studies seem to support the role of $L p(a)$ as an independent cardiovascular risk factor ${ }^{1,4,52}$. Indeed, cardiovascular risk assessment with $L p(a)$ at middle-age may include direct $L p(a)$ measurement or an $L P A$ genetic risk score, comprising 43 variants at the $L P A$ gene ${ }^{57}$. $L P A$ genetic risk score is able to discriminate people with the hyper-Lp(a) phenotype (i.e., high Lp(a) levels) and high risk for CAD even among closely related family members ${ }^{57}$. Hyper-Lp(a) phenotype frequently co-exists with other risk factors for CVD, such as familial hypercholesterolaemia or apolipoprotein E4-allele ${ }^{58-60}$. Indeed, hyper-Lp(a) phenotype is a frequent finding in $\mathrm{FH}$ subjects, especially in the presence of $\mathrm{CHD}^{58-60}$.

Individuals with heterozygous familial hypercholesterolaemia (HeFH) have almost 2.5-fold increased Lp(a) levels compared with controls ${ }^{61}$. It is suggested that $L p(a)$ has a binding affinity to LDLR but less than LDL due to apo(a) mask. Thus, its clearance may be decreased in HeFH patients ${ }^{62}$. Also, Lp(a) levels have been proposed as a marker of restenosis after percutaneous transluminal coronary angioplasty, saphenous vein bypass graft atherosclerosis and accelerated coronary atherosclerosis of cardiac transplantation ${ }^{63}$.

Moreover, various inflammatory conditions, such as rheumatoid arthritis, systemic lupus erythematosus, acquired immunodeficiency syndrome and pulmonary arterial hypertension are associated with high Lp(a) levels ${ }^{64}$. Particularly, in cases of rheumatoid arthritis interleukin- 6 receptor blockade by tocilizumab reverses high $L p(a)$ levels. This suggests that interleukin- 6 may have a potential role in regulating $L p(a)$ plasma levels ${ }^{64}$. Differences in $\mathrm{Lp}$ (a) levels have also been observed in pregnancy, another inflammatory condition ${ }^{65}$. Apart from inflammation, Lp(a) correlates inversely with bile acid levels in plasma in patients with biliary obstructions. It has been revealed that the activation of the Farnesoid $X$ Receptor by bile acids suppresses LPA mRNA transcription and therefore regulates plasma $L p(a)$ levels ${ }^{66}$.

Paradoxically, low levels of $L p(a)$ could be associated with increased risk of diabetes mellitus or bleeding ${ }^{34}$. One hypothesis is that the increased risk for diabetes results from the harmful trapping of large apo(a) isoforms in hepatocytes or other cells, and thus not from the low levels per $\mathrm{se}^{34}$. However, it remains possible that some patients with low $L p(a)$ levels could have increased risk for diabetes or bleeding because of some unidentified genetic or acquired predisposing cofactor that acts synergistically with low $\operatorname{Lp}(a)^{34}$.

Regarding pathophysiological mechanisms, Lp(a) may act via its LDL-like component ${ }^{67,68}$. Indeed, in some patients, a substantial fraction of LDL-cholesterol may be transported by $L p(a)$ particles rather than the archetypical LDL particle ${ }^{69}$. The LDL-like component of Lp(a) undergoes different types of modification after entry into the vessel wall $^{67,68}$. The atherogenic actions of LDL in the arterial tissue include the formation of macrophage-derived foam cells upon phagocytic uptake of aggregated LDL particles, or LDL in which lipid and/or protein components have undergone covalent modification, triggering uptake by scavenger receptors ${ }^{70}$. Also, they include the release of bioactive proinflammatory lipids exerting both local and systemic actions, the formation of extracellular lipid deposits, and induction of an adaptive immune response with the activation of antigen-specific T-cell responses and antibodies ${ }^{70}$. Additionally, LDL particles induce an innate immune response in the arterial wall, that involves damage associated molecular patterns (DAMPs). In turn, these DAMPs promote recruitment of immuno-inflammatory cells, such as monocyte-macrophages, neutrophils, lymphocytes, and dendritic cells, leading to local and potentially chronic inflammation. Cell death by apoptosis or necrosis can then be induced, thereby contributing to necrotic core formation ${ }^{70}$.

Moreover, Lp(a) may act via the antifibrinolytic/prothrombotic effects of apo(a). Apo(a) is highly homologous to PLG and its binding to plasminogen binding sites prevents interaction between PLG and tPA. If tPA cannot cleave plasminogen to plasmin, then fibrin clots cannot be dissolved ${ }^{71}$. Lp(a) also increases the production and activity of tissue plasminogen activator inhibitor-1 (PAI$1)^{72}$. Nonetheless, it is a competitor with both PLG and tPA for binding sites on fibrin, which subsequently promote a thrombotic state by preventing plasmin-mediated clot lysis. Indeed, smaller apo(a) isoforms display higher affinity binding to fibrin ${ }^{73}$. Thrombosis may be augmented by Lp(a) binding and then inhibiting tissue factor pathway inhibitor (TFPI), which is a potent inhibitor of the tissue factor mediated coagulation cascade ${ }^{74}$. Also, Lp(a) has been demonstrated to regulate platelet activation and aggregation triggered by various agonists, as well as to associate with others prothrombotic proteins, such as a2macroglobulin (a plasmin inhibitor) and serine proteinase inhibitor A1 (SERPINA, a tPA inhibitor) ${ }^{75}$.

$L p(a)$ is susceptible to oxidative stress, leading to the formation of pro-inflammatory and pro-atherogenic OxPLs, found on apoB, apo(a), and its lipid phase ${ }^{1,76}$. OxPLs induce proinflammatory signaling in endothelial cells, smooth muscle cells, monocytes, macrophages, dendritic cells, and platelets ${ }^{77-80}$. They also mediate plaquedestabilizing processes, and as they are present in higher quantities (70-fold) in plaque than in plasma, are capable of stimulating proinflammatory genes leading to vascular inflammation ${ }^{77-80}$. Additionally, OxPLs are pro-apoptotic 
in high concentrations, accumulate in atherosclerotic lesions and play an important role in atherosclerosis ${ }^{77-80}$. High Lp(a) and OxPLs of Lp(a) levels, through their proinflammatory and procalcific activity on valvular interstitial cells, are causally associated with increased valve calcification in elderly patients with advanced aortic stenosis, a faster hemodynamic progression of aortic stenosis, and increased risk of aortic valve replacement and death ${ }^{81,82}$. OxPL plasma levels correlate more strongly with high Lp(a) levels and small apo(a) isoforms, or with the presence of LPA SNPs rs3798220 and rs10455872, which are also correlated with high $L p(a)$ levels ${ }^{83,84}$.This association of OxPLs with small Lp(a) particles may at least partially explain their enhanced atherogenicity and association with higher CVD risk as compared with large ones ${ }^{85}$. Nevertheless, up to $90 \%$ of all OxPLs found in human lipoproteins are carried on $\mathrm{Lp}(\mathrm{a})$, which is not necessarily oxidized. Thus, OxPLs may impart additional and potent proinflammatory properties to $L p(a)$ and play a key role in $L p(a)$ functionality ${ }^{5,23}$. OxPLs are degraded into lysophosphatidylcholine (lyso-PC) and oxidized free fatty acids, which also manifest proinflammatory and proatherogenic effects by Lp-PLA 2 . Lp-PLA2, among other lipoproteins, is associated with $\operatorname{Lp}(a)^{85}$.However, the Lp-PLA2 associated with small apo(a) isoforms has a lower catalytic efficiency compared with the Lp-PLA2 associated with larger apo(a) isoforms. This could be another factor that favors the sequestration of plasma OxPLs on small apo(a) isoforms, and therefore the strong correlation between small apo(a) isoforms and high OxPL levels in plasma ${ }^{85}$.

Another biological property of $L p(a)$ that makes it a proatherogenic and a proinflammatory lipoprotein, is monocyte chemoattractant protein-1 (MCP-1). MCP-1 is a major chemokine involved in the development of atherosclerosis via monocyte recruitment to the vascular wall $^{86}$. Lp(a) in plasma may serve as a carrier for MCP-1, and OxPLs are major determinants of the MCP-1 binding $^{86}$. Once $L p(a)$ has entered the arterial intima with its associated MCP-1, it may subsequently enhance the trafficking of monocytes to the vascular wall, and thereby exacerbate lesion progression ${ }^{86}$. Furthermore, $\mathrm{Lp}(\mathrm{a})$ promotes the adhesion and transendothelial migration of monocytes, through the interaction of apo(a) with the b2-integrin Mac- ${ }^{87}$.

Last but not least, autotaxin (ATX) is another important molecule associated with Lp(a). ATX preferentially transported by $L p(a)$ catalyzes the hydrolysis of lyso-PC into lysophosphatidic acid (lyso-PA) ${ }^{88}$. As mentioned previously, lyso-PC is formed by hydrolysis of OxPLs, mediated by the Lp(a)-associated Lp-PLA2 ${ }^{85}$. Lyso-PA stimulates complex intracellular signaling pathways. As a result, it generates various cellular responses, such as inflammatory cytokine release, monocyte attraction and adhesion, abnormal endothelial cell behavior, endothelial permeability, and LDL uptake for plaque formation and participates in different pathophysiological conditions. Inflammation, atherogenesis and calcific aortic valve stenosis are among them ${ }^{88,89}$.

All these pathophysiological mechanisms of $\operatorname{Lp}(a)$, including proatherogenic, proinflammatory and antifibrinolytic mechanisms, probably contribute to cardiovascular risk in various but different extent in all age groups ${ }^{90}$. However, it is proposed that specific properties may predominate and manifest clinically in different age groups, with antifibrinolytic effects mainly in children, proinflammatory effects in young adults, and proatherogenic effects in the elderly ${ }^{90}$.

\section{Effect of hypolipidemic treatment on Lp(a)}

There are neither known non-pharmacologic methods, nor any specific pharmacological approaches able to lower $\mathrm{Lp}$ (a) concentrations to the extent proposed to achieve cardiovascular benefits ${ }^{91}$.

The effects of currently used therapeutic agents on circulating levels of $\operatorname{Lp}(\mathrm{a})$ are not well understood. Some of them, however, have a limited but clear effect on $L p(a)$. Lipoprotein apheresis is highly effective in reducing $L p(a)$ levels $(25-40 \%)^{92}$. Both statins ${ }^{93}$ and low-saturated fat diets $^{94}$ raise $L p(a)$ levels by approximately $10-30 \%$. On the other hand, fibrates ${ }^{95}$, and most hormones (except growth hormone) ${ }^{32,96}$ may reduce $L p(a)$ levels. Niacin ${ }^{97}$, mipomersen ${ }^{98}$, lomitapide ${ }^{99}$, proprotein convertase subtilisin kexin 9 (PCSK9) ${ }^{100-102}$ and (cholesteryl transfer protein) CETP inhibitors ${ }^{103}$, aspirin ${ }^{32}$, antibodies to interleukin- $6^{32}$, nutraceuticals ${ }^{104-107}$, tibolone ${ }^{108}$ and ezetimibe ${ }^{109}$, also, decrease $L p(a)$ levels. Vitamin $C^{110}$ and bile acid sequestrants ${ }^{111}$ have a neutral effect on plasma $L p(a)$ levels.

In the era of RNA-based therapies, novel medicines aimed at substantially lowering $L p(a)$ levels, using antisense oligonucleotides (ASOs) and small interfering RNAs (siRNA), are currently in clinical development ${ }^{91}$. ASOs targeting apo(a) have shown much promise with reductions up to $92.4 \%$ in $\mathrm{Lp}(\mathrm{a})$ in a dose dependent fashion and a favorable safety profile ${ }^{3,112,113}$. AMG 890 (olpasiran), a siRNA, reduced $L p(a)$ with observed maximal percent reductions of $>90 \%$ in a phase I study ${ }^{114}$.

In the following table, we review the established and emerging therapeutic agents that affect $L p(a)$ levels. (Table)

\section{Conclusion and future perspective}

$\mathrm{Lp}(\mathrm{a})$ offers a fresh look at atherosclerotic CVD, as high $\mathrm{Lp}(\mathrm{a})$ levels seem to be associated with an increased risk of CVD. On the contrary, the role of low $L p(a)$ levels 
TABLE. Current and emerging Lipoprotein(a)-lowering therapies

\begin{tabular}{|c|c|}
\hline Lipoprotein(a)-lowering therapy & Lipoprotein(a) effect \\
\hline Lipoprotein apheresis & $\begin{array}{l}\text { Acute decrement of } 70 \% \text { to } 75 \% \text {, but regular apheresis can translate into a } \\
\text { mean } L p(a) \text { reduction between } 25 \% \text { to } 40 \% \text {. }\end{array}$ \\
\hline Statins & $\begin{array}{l}\text { Most statins may increase } L p(a) \text { on average } 8 \% \text { to } 24 \% \text {, although significant } \\
\text { heterogeneity in response is present. }\end{array}$ \\
\hline Low-saturated fat diets & Potential increment between $10 \%$ to $20 \%$. \\
\hline Fibrates & $\begin{array}{l}\text { Potent reduction between } 10 \% \text { to } 40 \% \text {. However, they are not the drugs of } \\
\text { choice for managing } L p(a) \text { elevations. }\end{array}$ \\
\hline Sex hormone therapies (e.g. estrogen) & $\begin{array}{l}\text { Lp(a) reduction by approximately } 20 \% \text {. However, hormone replacement } \\
\text { therapy cannot be recommended for the sole purpose of lowering } L p(a) \text {. }\end{array}$ \\
\hline Tibolone & Lp(a) reduction between $13,2 \%$ and $29 \%$. \\
\hline Vitamin C & Neutral effect on Lp(a) plasma levels. \\
\hline Bile acid sequestrants & Neutral effect on Lp(a) plasma levels. \\
\hline Nicotinic acid (niacin) & $\begin{array}{l}\text { Potential } L p(a) \text { lowering effect between } 20 \% \text { to } 30 \% \text {, but it is limited by side } \\
\text { effects. }\end{array}$ \\
\hline Ezetimibe & As monotherapy provides a modest $7 \%$ reduction in $L p(a)$ levels. \\
\hline Mipomersen & $20 \%-40 \%$ reduction, although the product is not clinically available. \\
\hline Lomitapide & $17 \%$ reduction. \\
\hline Inhibitors of cholesteryl transfer protein (CETP inhibitors) & $25 \%-40 \%$ reduction, although not approved for clinical use. \\
\hline Thyromimetic eprotirome & $\begin{array}{l}\text { Lp(a) decrement between } 20 \% \text { to } 30 \% \text {, although not approved for clinical use } \\
\text { (investigational agent). }\end{array}$ \\
\hline Aspirin & Modest reduction up to $30 \%$. \\
\hline Antibodies to interleukin- 6 & Modest reduction up to $30 \%$. \\
\hline Nutraceuticals (L-carnitine, coenzyme Q10, xuezhikang) & Potential Lp(a)-lowering effects between $10 \%$ to $30 \%$. \\
\hline $\begin{array}{l}\text { Proprotein convertase subtilisin kexin } 9 \text { (PCSK9) inhibitors: } \\
\text { - Monoclonal antibodies: evolocumab, alirocumab } \\
\text { - Antisense: inclisiran }\end{array}$ & $\begin{array}{l}\text { - Mean reduction of } L p(a) \text { levels between } 14 \% \text { to } 30 \% \text {. } \\
\text { - Mean reduction of } L p(a) \text { levels between } 15 \% \text { to } 25 \% \text {. }\end{array}$ \\
\hline $\begin{array}{l}\text { Antisense oligonucleotides (ASOs): } \\
\text { - ISIS-Apo(a)RX } \\
\text { - IONIS-Apo(a)RX } \\
\text { - IONIS-Apo(a)LRX (pelacarsen=TQJ230) }\end{array}$ & $\begin{array}{l}\text { - Mean percentage decreases in plasma } L p(a) \text { concentrations of } 40 \% \text { to } 78 \% \text {. } \\
\text { - Mean percentage decreases in plasma } L p(a) \text { concentrations of } 67 \% \text { to } 72 \% \text {. } \\
\text { - } L p(a) \text { reductions up to } 92 \% \text {. }\end{array}$ \\
\hline $\begin{array}{l}\text { Small interfering RNAs (siRNAs): } \\
\text { - Olpasiran (AMG890) }\end{array}$ & - Observed maximum reduction of $>90 \%$. \\
\hline
\end{tabular}

in humans is still not fully elucidated. Several mechanisms to explain the atherogenicity of $\operatorname{Lp}(a)$ have been proposed so far, including primarily its LDL and apo(a) components and associated OxPLs. However, since we have no commercially available drugs that selectively reduce high $L p(a)$ levels, it is not possible to draw safe conclusions on the clinical importance for reducing $\mathrm{Lp}(\mathrm{a})$ as well as for the exact pathophysiological role of this lipoprotein.

\section{Acknowledgement}

The present study was supported by a research grant from the Hellenic Atherosclerosis Society which was received by Koutsogianni Amalia Despoina.

\section{Conflict of Interest}

The authors have no conflicts of interest related to this publication. 


\title{
ПЕРІАНЧН
}

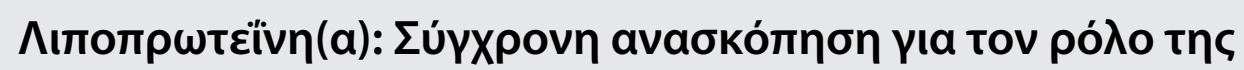

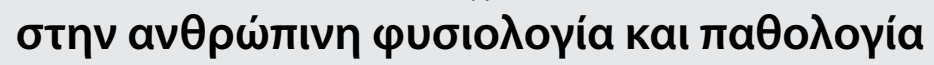

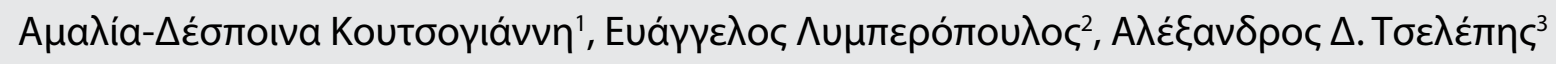

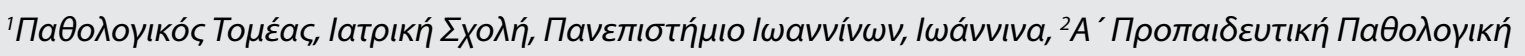

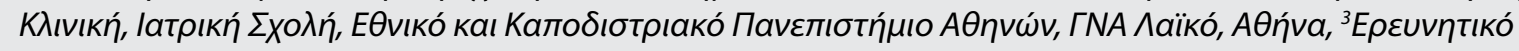

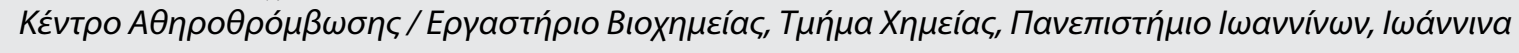

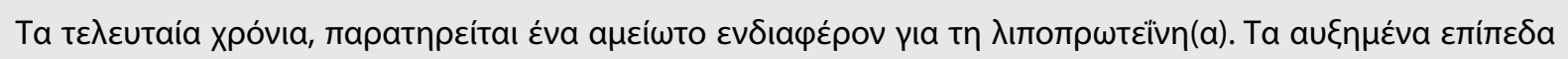

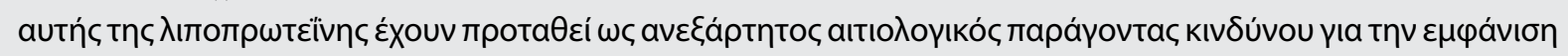

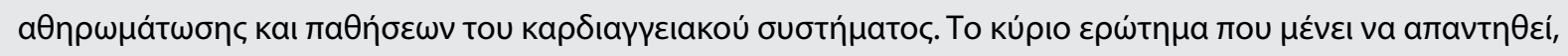

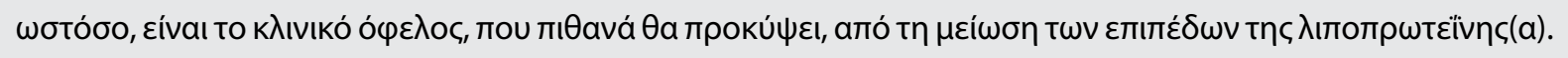

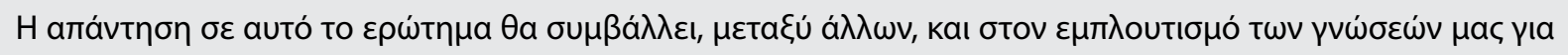

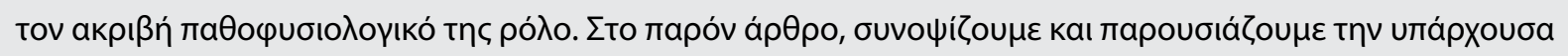

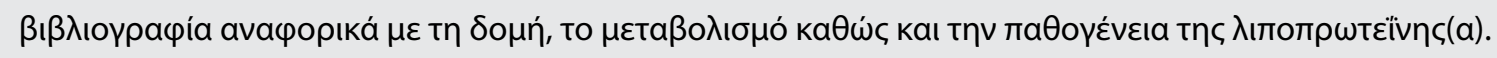

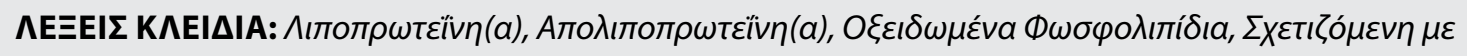

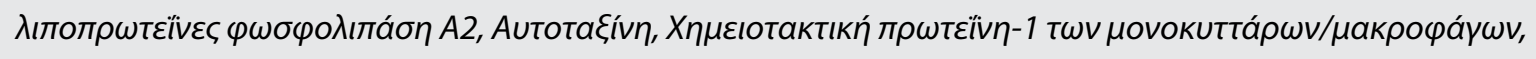

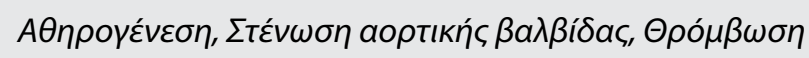

\section{REFERENCES}

1. Gencer B, Kronenberg F, Stroes ES, Mach F. Lipoprotein(a): the revenant. Eur Heart J. 2017 May;38(20):1553-60.

2. Vuorio A, Watts GF, Kovanen PT. Depicting new pharmacological strategies for familial hypercholesterolaemia involving lipoprotein(a). Eur Heart J. 2017 Dec;38(48):355559.

3. Tsimikas S, Karwatowska-Prokopczuk E, Gouni-Berthold I, Tardif JC, Baum SJ, Steinhagen-Thiessen E, et al. Lipoprotein(a) Reduction in Persons with Cardiovascular Disease. N Engl J Med. 2020 Jan;382(3):244-55.

4. Cegla J, Neely RDG, France M, Ferns G, Byrne CD, Halcox J, et al. HEART UK consensus statement on Lipoprotein(a): A call to action. Atherosclerosis. 2019 Dec;291:62-70.

5. Bergmark C, Dewan A, Orsoni A, Merki E, Miller ER, Shin MJ, et al. A novel function of lipoprotein [a] as a preferential carrier of oxidized phospholipids in human plasma. J Lipid Res. 2008 Oct;49(10):2230-9.

6. Taleb A, Witztum JL, Tsimikas S. Oxidized phospholipids on apolipoprotein B-100 (OxPL/apoB) containing lipoproteins: a biomarker predicting cardiovascular disease and cardiovascular events. Biomark Med. 2011 Oct;5(5):673-94.

7. Jawi MM, Frohlich J, Chan SY. Lipoprotein(a) the insurgent: A new insight into the structure, function, metabolism, pathogenicity, and medications affecting lipoprotein(a) molecule. J Lipids [Internet]. 2020 Feb [accessed 2021 Jun 23];2020:3491764. Available from: https://pubmed. ncbi.nlm.nih.gov/32099678/

8. Tsimikas S. A Test in context: lipoprotein(a): Diagnosis, prognosis, controversies, and emerging therapies. J Am Coll Cardiol. 2017 Feb;69(6):692-711.
9. Ellis KL, Boffa MB, Sahebkar A, Koschinsky ML, Watts GF. The renaissance of lipoprotein(a): Brave new world for preventive cardiology? Prog Lipid Res. 2017 Oct;68:57-82.

10. Schmidt K, Noureen A, Kronenberg F, Utermann G. Structure, function and genetics of lipoprotein(a). J Lipid Res. 2016 Aug;57(8):1339-59.

11. Coassin S, Erhart G, Weissensteiner $H$, Guimarães de Araújo ME, Lamina C, Schönherr S, et al. A novel but frequent variant in LPA KIV-2 is associated with a pronounced $\mathrm{Lp}(\mathrm{a})$ and cardiovascular risk reduction. Eur Heart J. 2017 Jun;38(23):1823-31.

12. Di Maio S, Grüneis R, Streiter G, Lamina C, Maglione M, Schoenherr $S$, et al. Investigation of a nonsense mutation located in the complex KIV-2 copy number variation region of apolipoprotein(a) in 10,910 individuals. Genome Med. 2020 Aug;12(1):74.

13. Hobbs $\mathrm{HH}$, White AL. Lipoprotein: Intrigues and insights. Curr Opin Lipidol. 1999 Jun;10(3):225-36.

14. Schachtl-Riess JF, Kheirkhah A, Grüneis R, Di Maio S, Schoenherr S, Streiter G, et al. Frequent LPA KIV-2 Variants Lower Lipoprotein(a) Concentrations and protect against coronary artery disease. J Am Coll Cardiol. 2021 Aug;78(5):437-49.

15. Koschinsky ML, Boffa MB. Genetics to the Rescue: Sophisticated Approaches Provide Critical Insights Into the Determination of Lp(a) Levels. J Am Coll Cardiol. 2021 Aug;78(5):450-52.

16. Dubé JB, Boffa MB, Hegele RA, Koschinsky ML. Lipoprotein(a): More interesting than ever after 50 years. Curr Opin Lipidol. 2012 Apr;23(2):133-40.

17. Kronenberg F, Utermann G. Lipoprotein(a): Resurrected 
by genetics. J Intern Med. 2013 Jan;273(1):6-30.

18. Hoover-Plow J, Huang M. Lipoprotein(a) metabolism: Potential sites for therapeutic targets. Metabolism. 2013 Apr;62(4):479-91.

19. Rahman MN, Becker L, Petrounevitch V, Hill BC, Jia Z, Koschinsky ML. Comparative analyses of the lysine binding site properties of apolipoprotein(a) kringle IV types 7 and 10. Biochemistry. 2002 Jan;41(4):1149-55.

20. Harpel PC, Gordon BR, Parker TS. Plasmin catalyzes binding of lipoprotein(a) to immobilized fibrinogen and fibrin. Proc Natl Acad Sci. 1989 May;86(10):3847-51.

21. Ernst A, Helmhold M, Brunner C, Pethö-Schramm A, Armstrong VW, Müller HJ. Identification of two functionally distinct lysine-binding sites in kringle 37 and in kringles 32-36 of human apolipoprotein(a). J Biol Chem. 1995 Mar;270(11):6227-34.

22. Gabel BR, May LF, Marcovina SM, Koschinsky ML. Lipoprotein(a) assembly. Quantitative assessment of the role of apo(a) kringle IV types 2-10 in particle formation. Arterioscler Thromb Vasc Biol. 1996 Dec;16(12):1559-67.

23. Leibundgut $G$, Scipione $C$, Yin $H$, Schneider $M$, Boffa $M B$, Green S, et al. Determinants of binding of oxidized phospholipids on apolipoprotein (a) and lipoprotein (a). J Lipid Res. 2013 Oct;54(10):2815-30.

24. Scipione CA, Sayegh SE, Romagnuolo R, Tsimikas $S$, Marcovina SM, Boffa MB, et al. Mechanistic insights into Lp(a)-induced IL-8 expression: A role for oxidized phospholipid modification of apo(a). J Lipid Res. 2015 Dec;56(12): 2273-85.

25. Rader DJ, Cain W, Ikewaki K, Talley G, Zech LA, Usher $D$, et al. The inverse association of plasma lipoprotein(a) concentrations with apolipoprotein(a) isoform size is not due to differences in $\mathrm{Lp}(\mathrm{a})$ catabolism but to differences in production rate. J Clin. Invest. 1994 Jun;93(6): 2758-63.

26. Hofmann SL, Eaton DL, Brown MS, McConathy WJ, Goldstein JL, Hammer RE. Overexpression of human low density lipoprotein receptors leads to accelerated catabolism of Lp(a) lipoprotein in transgenic mice. J Clin Invest. 1990 May;85(5):1542-47.

27. Romagnuolo R, Scipione CA, Boffa MB, Marcovina SM, Seidah NG, Koschinsky ML. Lipoprotein(a) catabolism is regulated by proprotein convertase subtilisin/kexin type 9 through the low-density lipoprotein receptor. J Biol Chem. 2015 May;290(18):11649-62.

28. Raal FJ, Giugliano RP, Sabatine MS, Koren MJ, Blom D, Seidah NJ, et al. PCSK9 inhibition-mediated reduction in Lp(a) with evolocumab: an analysis of 10 clinical trials and the LDL receptor's role. J Lipid Res. 2016 Jun;57(6):1086-96.

29. Tam SP, Zhang X, Koschinsky ML. Interaction of a recombinant form of apolipoprotein[a] with human fibroblasts and with the human hepatoma cell line HepG2. J Lipid Res. 1996 Mar;37(3):518-33.

30. Sharma M, Redpath GM, Williams MJ, McCormick SPA. Recycling of apolipoprotein(a) after PlgRKT-mediated endocytosis of lipoprotein(a). Circ Res. 2017 Mar;120(7):1091102.

31. Yang XP, Amar MJ, Vaisman B, Bocharov AV, Vishnyakova TG, Freeman LA, et al. Scavenger receptor-BI is a receptor for lipoprotein(a). J Lipid Res. 2013 Sep;54(9):2450-7.

32. Tsimikas S, Fazio S, Ferdinand KC, Ginsberg HN, Koschinsky ML, Marcovina SM, et al. NHLBI working group recom- mendations to reduce lipoprotein(a)-mediated risk of cardiovascular disease and aortic stenosis. J Am Coll Cardiol. 2018 Jan;71(2):177-92.

33. Lippi G, Guidi G. Lipoprotein(a): From ancestral benefit to modern pathogen? QJM. 2000 Feb;93(2):75-84.

34. Langsted A, Nordestgaard BG, Kamstrup PR. Low lipoprotein(a) levels and risk of disease in a large, contemporary, general population study. Eur Heart J. 2021 Mar;42(12):1147-56.

35. Kostner KM, Kostner GM. Therapy of Hyper-Lp (a). Handb Exp Pharmacol. 2005;170:519-536.

36. Kim JS, Chang JH, Yu HK, Ahn JH, Yum JS, Lee SK, et al. Inhibition of angiogenesis and angiogenesis-dependent tumor growth by the cryptic kringle fragments of human apolipoprotein (a). J Biol Chem. 2003 Aug;278(31):290008.

37. Schulter V, Koolwijk P, Peters E, Frank S, Hrzenjak A, Graier WF, et al. Impact of apolipoprotein (a) on in vitro angiogenesis. Arterioscler Thromb Vasc Biol. 2001 Mar;21(3):433-8.

38. Siekmeier R, Scharnagl H, Kostner GM, GrammarT, Stojakovic T, März W. Lipoprotein (a) - structure, epidemiology, function and diagnostics of a cardiovascular risk marker. The Open Clinical Chemistry Journal. 2008 Nov;1:79-91.

39. Yano Y, Shimokawa K, Okada Y, Noma A. Immunolocalization of lipoprotein (a) in wounded tissues. J Histochem Cytochem. 1997 Apr;45(4):559-68.

40. Anglıs-Cano E, De la Pepa DA, Loyau S. Inhibition of fibrinolysis by lipoprotein(a). Ann N Y Acad Sci. 2001;936:261-75.

41. Loscalzo J, Weinfeld M, Fless GM, Scanu MA. Lipoprotein (a), fibrin binding, and plasminogen activation. Arteriosclerosis. 1990 Mar-Apr;10(2):240-5.

42. Etingin OR, Hajjar DP, Hajjar KA, Harpel PC, Nachman RL. Lipoprotein (a) regulates plasminogen activator inhibitor-1 expression in endothelial cells. A potential mechanism in thrombogenesis. J Biol Chem. 1991 Feb;266(4):2459-65.

43. Missala I, Kassner U, Steinhagen-Thiessen E. A systematic literature review of the association of lipoprotein (a) and autoimmune diseases and atherosclerosis. Int J Rheumatol [Internet]. 2012 Dec [accessed 2021 Jun 11];2012(1):480784. Available from: https://pubmed. ncbi.nlm.nih.gov/23304154/

44. Riches K, Porter KE. Lipoprotein (a): Cellular effects and molecular mechanisms. Cholesterol [Internet]. 2012 Sept [accessed 2021 Jun 11];2012:923289. Available from: https://pubmed.ncbi.nlm.nih.gov/22991657/

45. Utermann G. Lipoprotein(a). In Metabolic and Molecular Bases of Inherited Disease. 2001 st ed. Mc-Graw-Hill, Medical Publishing Division; 2006. p2753-87.

46. Lippi G, Braga V, Adami S, Guidi G. Modification of serum apolipoprotein $\mathrm{Al}$, apolipoprotein $\mathrm{B}$ and lipoprotein (a) levels after bisphosphonates-induced acute phase response. Clin Chim Acta. 1998 Mar;271(1):79-87.

47. Ramharack R, Barkalow D, Spahr MA. Dominant negative effect of TGF- $\beta 1$ and TNF- $\alpha$ on basal and IL-6-induced lipoprotein (a) and apolipoprotein (a) mRNA expression in primary monkey hepatocyte cultures. Arterioscler Thromb Vasc Biol. 1998 Jun;18(6):984-90.

48. Liberopoulos EN, Apostolou F, Gazi IF, Kostara C, Bairaktari $E T$, Tselepis AD, et al. Visceral leishmaniasis is associated with marked changes in serum lipid profile. Eur J Clin 
Invest. 2014 Aug;44(8):719-27.

49. Filippas-Ntekouan S, Liberopoulos E, Elisaf M. Lipid testing in infectious diseases: possible role in diagnosis and prognosis. Infection. 2017 Oct;45(5):575-88.

50. Mooser V, Berger MM, Tappy L, Cayeux C, Marcovina SM, Darioli $R$, et al. Major reduction in plasma $L p(a)$ levels during sepsis and burns. Arterioscler Thromb Vasc Biol. 2000 Apr;20(4):1137-42.

51. Tsimikas S, Witztum JL. The role of oxidized phospholipids in mediating lipoprotein(a) atherogenicity. Curr Opin Lipidol. 2008 Aug;19(4):369-77.

52. Gencer B, Mach F. Lipoprotein(a): the perpetual supporting actor. Eur Heart J. 2018 Jul;39(27):2597-99.

53. Nordestgaard BG, Langsted A. Lipoprotein (a) as a cause of cardiovascular disease: Insights from epidemiology, genetics, and biology. J Lipid Res. 2016 Nov;57(11):1953-75.

54. Malaguarnera G, Gagliano C, Bucolo C, Vacante M, Salomone $S$, Malaguarnera $M$, et al. Lipoprotein(a) serum levels in diabetic patients with retinopathy. Biomed Res Int [Internet]. 2013 Jun [accessed 2021 Apr 14];2013:943505. Available from: https://pubmed.ncbi. nlm.nih.gov/23862162/

55. Emdin CA, Khera AV, Natarajan P, Klarin D, Won HH, Peloso GM, et al. Phenotypic characterization of genetically lowered human lipoprotein(a) levels. J Am Coll Cardiol. 2016 Dec;68(25):2761-72.

56. Arnold M, Schweizer J, Nakas CT, Schütz V, Westphal LP, Inauen C, et al. Lipoprotein(a) is associated with large artery atherosclerosis stroke aetiology and stroke recurrence among patients below the age of 60 years: Results from the BIOSIGNAL study. Eur Heart J. 2021 Jun;42(22):2186-96.

57. Trinder $M$, Uddin $M$, Finneran $P$, Aragam KG, Natarajan P. Clinical utility of lipoprotein(a) and LPA genetic risk score in risk prediction of incident atherosclerotic cardiovascular disease. JAMA Cardiol. 2020 Oct;6(3):1-9.

58. Orsó E, Ahrens N, Kilali'c D, Schmitz G. Familial hypercholesterolemia and lipoprotein(a) hyperlipidemia as independent and combined cardiovascular risk factors. Atheroscler Suppl. 2009 Dec;10(5):74-8.

59. Schmitz G, Orsó E. Lipoprotein(a) hyperlipidemia as cardiovascular risk factor: pathophysiological aspects. Clin Res Cardiol Suppl. 2015;10(Suppl 1):21-5.

60. Anastasiou G, Sakka E, Blathra E, Kalivi A, Elisaf M, Liamis $G$, et al. Lipoprotein(a): A concealed precursor of increased cardiovascular risk? A real-world regional lipid clinic experience. Arch Med Res. 2021;52(4):397-404.

61. Anagnostis $P$, Siolos $P$, Krikidis D, Goulis DG, Stevenson JC. Should we consider lipoprotein (a) in cardiovascular disease risk assessment in patients with familial hypercholesterolaemia? Curr Pharm Des. 2018;24(31):3665-71.

62. McCormick SPA, Schneider WJ. Lipoprotein(a) catabolism: A case of multiple receptors. Pathology. 2019 Feb;51(2):155-164.

63. Malaguarnera M, Vacante M, Russo C, Malaguarnera G, Antic T, Malaguarnera L, et al. Lipoprotein(a) in cardiovascular diseases. Biomed Res Int [Internet]. 2013 Dec [accessed 2021 Jun 14];2013:650989. Available from: https://www. ncbi.nlm.nih.gov/pmc/articles/PMC3591100/

64. Reyes-Soffer G, Westerterp M. Beyond Lipoprotein(a) plasma measurements: Lipoprotein(a) and inflammation.
Pharmacol Res [Internet]. 2021 Jul [accessed 2021 Aug 19];169:105689. Available from: https://pubmed.ncbi. nlm.nih.gov/34033878/

65. Fanshawe $A E$, Ibrahim M. The current status of lipoprotein (a) in pregnancy: A literature review. J Cardiol. 2013 Feb;61(2):99-106.

66. Chennamsetty I, Claudel T, Kostner KM, Baghdasaryan A, Kratky D, Levak-Frank S, et al. Farnesoid X receptor represses hepatic human APOA gene expression. J Clin Invest. [Internet]. 2011 Sep [accessed 2021 Aug 27];121(9):3724-34. Available from: https://www.ncbi. nlm.nih.gov/pmc/articles/PMC3163948/

67. Kattoor AJ, Kanuri SH, Mehta JL. Role of Ox-LDL and LOX-1 in Atherogenesis. Curr Med Chem. 2019;26(9):1693-700.

68. Hartley A, Haskard D, Khamis R. Oxidized LDL and antioxidized LDL antibodies in atherosclerosis - Novel insights and future directions in diagnosis and therapy. Trends Cardiovasc Med. 2019 Jan;29(1):22-6.

69. Rosenson RS, Goonewardena SN. The residual risk Odyssey: From LDL to Lp(a). J Am Coll Cardiol. 2021 Aug;78(5):434-6.

70. Borén B, Chapman MJ, Krauss RM, Packard CJ, Bentzon $\mathrm{JF}$, Binder CJ, et al. Low-density lipoproteins cause atherosclerotic cardiovascular disease: Pathophysiological, genetic, and therapeutic insights: A consensus statement from the European Atherosclerosis Society Consensus Panel. Eur Heart J. 2020 Jun;41(24):2313-30.

71. Boffa MB, Koschinsky ML. Lipoprotein (a): Truly a direct prothrombotic factor in cardiovascular disease? J Lipid Res. 2016 May;57(5):745-57.

72. Aznar J, Estelles A, Breto M, Espana F. Euglobulin clot lysis induced by tissue-type plasminogen-activator in subjects with increased levels and different isoforms of lipoprotein (a). Thromb Res. 1993 Dec;72(5):459-65.

73. Angles-Cano E, de la Pena Diaz A, Loyau S. Inhibition of fibrinolysis by lipoprotein(a). Ann N Y Acad Sci. 2001 Jun;936(1):261-75.

74. Pan SC, Kleppe LS, Witt TA, Mueske CS, Simari RD. The effect of vascular smooth muscle cell-targeted expression of tissue factor pathway inhibitor in a murine model of arterial thrombosis. Thromb Haemost. 2004 Sep;92(3):495-502.

75. Derijke YB, Jurgens G, Hessels EM, Hermann A, Vanberkel TJC. In vivo fate and scavenger receptor recognition of oxidized lipoprotein[a] isoforms in rats. J Lipid Res. 1992 Sep;33(9):1315-25.

76. Bergmark C, Dewan A, Orsoni A, Merki E, Miller ER, Shin MJ, et al. A novel function of lipoprotein [a] as a preferential carrier of oxidized phospholipids in human plasma. J Lipid Res. 2008 Oct;49(10):2230-9.

77. Berliner JA, Leitinger N, Tsimikas S. The role of oxidized phospholipids in atherosclerosis. J Lipid Res. 2009 Apr;50(Suppl):S207-12.

78. Tsimikas S, Witztum JL. The role of oxidized phospholipids in mediating lipoprotein (a) atherogenicity. Curr Opin Lipidol. 2008 Aug;19(4):369-77.

79. Capoulade R, Mahmut A, Tastet L, Arsenault M, Bédard E, Dumesnil JG, et al. Impact of plasma Lp-PLA2 activity on the progression of aortic stenosis the PROGRESSA study. JACC Cardiovasc Imaging. 2015 Jan;8(1):26-33.

80. Bochkov VN, Oskolkova OV, Birukov KG, Levonen AL, Binder CJ, Stöckl J. Generation and biological activities of 
oxidized phospholipids. Antioxid Redox Signal. 2010 Apr;12(8):1009-59.

81. Kamstrup PR, Hung MY, Witztum JL, Tsimikas S, Nordestgaard BG. Oxidized phospholipids and risk of calcific aortic valve disease: The Copenhagen general population study. Arterioscler Thromb Vasc Biol. 2017 Aug;37(8):1570-8.

82. Capoulade R, Yeang C, Chan KL, Pibarot P, Tsimikas S. Association of mild to moderate aortic valve stenosis progression with higher lipoprotein(a) and oxidized phospholipid levels: Secondary analysis of a randomized clinical trial. JAMA Cardiol. 2018 Dec;3(12):1212-17.

83. Arai K, Luke MM, Koschinsky ML, Miller ER, Pullinger CR, Witztum JL, et al. The 14399M variant of apolipoprotein(a) is associated with increased oxidized phospholipids on apolipoprotein B-100 particles. Atherosclerosis. 2010 Apr;209(2):498-503.

84. Rao F, Schork AJ, Maihofer AX, Nievergelt CM, Marcovina $S$, Miller ER, et al. Heritability of biomarkers of oxidized lipoproteins: Twin pair study. Arterioscler Thromb Vasc Biol. 2015 Jul;35(7):1704-11.

85. Tselepis AD. Oxidized phospholipids and lipoproteinassociated phospholipase $\mathrm{A} 2$ as important determinants of $L p(a)$ functionality and pathophysiological role. J Biomed Res. 2018 Jan;32(1):13-22.

86. Wiesner $\mathrm{P}$, Tafelmeier M, Chittka D, Choi SH, Zhang L, Byun YS, et al. MCP-1 binds to oxidized LDL and is carried by lipoprotein(a) in human plasma. J Lipid Res. 2013 Jul;54(7):1877-83.

87. Sotiriou SN, Orlova VV, Al-Fakhri N, Ihanus E, Economopoulou $M$, Isermann $B$, et al. Lipoprotein(a) in atherosclerotic plaques recruits inflammatory cells through interaction with Mac-1 integrin. FASEB J. 2006 Jan;20:559-561.

88. Yung YC, Stoddard NC, Chun J. LPA receptor signaling: pharmacology, physiology, and pathophysiology. J Lipid Res. 2014 Jul;55(7):1192-214.

89. De Oliveira Sá MPB, Cavalcanti LRP, Perazzo ÁM, Gomes RAF, Clavel MA, Pibarot $P$, et al. Calcific aortic valve stenosis and atherosclerotic calcification. Current Atherosclerosis Reports. 2020 Jan;22(2):2.

90. Tsimikas S. Elevated lipoprotein(a) and the risk of stroke in children, young adults, and the elderly. Eur Heart J. 2021 Jun;42(22):2197-200.

91. Greco MF, Sirtori CR, Corsini A, Ezhov M, Sampietro T, Ruscica M. Lipoprotein(a) lowering-from lipoprotein apheresis to antisense oligonucleotide approach. J Clin Med. 2020 Jul;9(7):2103.

92. Waldmann E, Parhofer KG. Lipoprotein apheresis to treat elevated lipoprotein (a). J Lipid Res. 2016 Oct;57(10):17517.

93. Tsimikas S, Gordts P, Nora C, Yeang C, Witztum JL. Statin therapy increases lipoprotein(a) levels. Eur Heart J. 2020 Jun;41(24):2275-84.

94. Yeang C, Hung MY, Byun YS, Clopton P, Yang X, Witztum $\mathrm{JL}$, et al. Effect of therapeutic interventions on oxidized phospholipids on apolipoprotein B100 and lipoprotein(a). J Clin Lipidol. 2016 May-Jun;10(3):594-603.

95. Sahebkar A, Simental-Mendia LE, Watts GF, Serban MC, Banach M, Lipid and blood pressure meta-analysis collaboration (LBPMC) group. Comparison of the effects of fibrates versus statins on plasma lipoprotein(a) concentrations: A systematic review and meta-analysis of head-to-head randomized controlled trials. BMC Med. 2017 Feb;15(1):22.

96. Ladenson PW, Kristensen JD, Ridgway EC, Olsson AG, Carlsson B, Klein I, et al. Use of the thyroid hormone analogue eprotirome in statin-treated dyslipidemia. $\mathrm{N}$ Engl J Med. 2010 Mar;362(10):906-16.

97. Guyton JR. Niacin in cardiovascular prevention: mechanisms, efficacy, and safety. Curr Opin Lipidol. 2007 Aug;18(4):415-20.

98. Christodoulakos GE, Lambrinoudaki IV, Panoulis CP, Papadias CA, Kouskouni EE, Creatsas GC. Effect of hormone replacement therapy, tibolone and raloxifene on serum lipids, apolipoprotein A1, apolipoprotein B and lipoprotein(a) in Greek postmenopausal women. Gynecol Endocrinol. 2004 May;18(5):244-57.

99. Tsimikas S, Witztum J, Catapano A. Effect of mipomersen on lipoprotein(a) in patients with hypercholesterolemia across four phase III studies. J Am Coll Cardiol. 2012;59:E1494.

100. Rader DJ, Kastelein JJ. Lomitapide and mipomersen:Two first-in-class drugs for reducing low-density lipoprotein cholesterol in patients with homozygous familial hypercholesterolemia. Circulation. 2014 Mar;129(9):1022-32.

101.O'Donoghue ML, Fazio S, Giugliano RP, Stroes ESG, Kanevsky E, Gouni-Berthold I, et al. Lipoprotein(a), PCSK9 Inhibition, and cardiovascular Risk. Circulation. 2019 Mar;139(12):1483-92.

102. Bittner VA, Szarek M, Aylward PE, Bhatt DL, Diaz R, Edelberg JM, et al. Effect of alirocumab on lipoprotein(a) and cardiovascular risk after acute coronary syndrome. J Am Coll Cardiol. 2020 Jan;75(2):133-44.

103. Ray KK, Wright RS, Kallend D, Koenig W, Leiter LA, Raal FJ, et al. Two phase 3 trials of inclisiran in patients with elevated Idl cholesterol. N Engl J Med. 2020 Apr;382(16):1507-19.

104. Puri R, Nissen SE, Arsenault BJ, John JSt, Riesmeyer JS, Ruotolo G, et al. Effect of C-reactive protein on lipoprotein(a)associated cardiovascular risk in optimally treated patients with high-risk vascular disease: A prespecified secondary analysis of the ACCELERATE trial. JAMA Cardiol. 2020 Oct;5(10):1136-43.

105.Sahebkar A, Simental-Mendia LE, Stefanutti C, Pirro M. Supplementation with coenzyme Q10 reduces plasma lipoprotein(a) concentrations but not other lipid indices: A systematic review and metaanalysis. Pharmacol Res. 2016 Mar;105:198-209.

106.Liu L, Zhao SP, Cheng YC, Li YL: Xuezhikang decreases serum lipoprotein(a) and C-reactive protein concentrations in patients with coronary heart disease. Clin Chem. 2003 Aug;49(8):1347-52.

107. Momtazi-Borojeni AA, Katsiki N, Pirro M, Banach M, Rasadi KA, Sahebkar A. Dietary natural products as emerging lipoprotein(a)-lowering agents. J Cell Physiol. 2019 Aug;234(8):12581-94.

108. Florentin M, Elisaf MS, Rizos CV, Bilianou E, Pitsavos C, Liberopoulos EN: L-Carnitine/Simvastatin reduces lipoprotein (a) levels compared with simvastatin monotherapy: A randomized double-blind placebo-controlled study. Lipids. 2017 Jan;52(1):1-9.

109. Awad K, Mikhailidis DP, Katsiki N, Muntner P, Banach M. Lipid and blood pressure meta-analysis collaboration (LBPMC) group. Effect of ezetimibe monotherapy on 
plasma lipoprotein(a) concentrations in patients with primary hypercholesterolemia: A systematic review and meta-analysis of randomized controlled trials. Drugs. 2018 Mar;78(4):453-62.

110. Jenner JL, Jacques PF, Seman LJ, Schaefer EJ. Ascorbic acid supplementation does not lower plasma lipoprotein(a) concentrations. Atherosclerosis. 2000 Aug;151(2):541-4.

111. Nozue T, Michishita I, Mizuguchi I. Effects of ezetimibe on remnant-like particle cholesterol, lipoprotein (a), and oxidized low-density lipoprotein in patients with dyslipidemia. J Atheroscler Thromb. 2010 Feb;17(1):37-44.

112. Tsimikas S, Viney NJ, Hughes SG, Singleton W, Graham MJ, Baker BF, et al. Antisense therapy targeting apolipoprotein(a): a randomised, double-blind, placebo-controlled phase 1 study. Lancet. 2015
Oct;386(10002):1472-83.

113. Viney NJ, van Capelleveen JC, Geary RS, Xia S, Tami JA, Yu RZ, et al. Antisense oligonucleotides targeting apolipoprotein(a) in people with raised lipoprotein(a): two randomised, double-blind, placebo-controlled, dose-ranging trials. Lancet [Internet]. 2016 Nov [accessed 2021 Feb 17];388(10057):2239-53. Available from: https:// pubmed.ncbi.nlm.nih.gov/27665230/

114. Koren MJ, Moriarty PM, Neutel J, Baum SJ, Hernandez-Illas M, Weintraub HS, et al. Abstract 13951: Safety, Tolerability and Efficacy of Single-dose Amg 890, a Novel Sirna Targeting $L p(a)$, in Healthy Subjects and Subjects With Elevated Lp(a). Circulation [Internet]. 2020 Nov [accessed 2021 Feb 19];142:A13951. Available from: https://www. ahajournals.org/doi/abs/10.1161/circ.142.suppl_3.13951 